\title{
Relationship between Cardiopulmonary Bypass Time, Platelet Count, Fibrinogen, ROTEM Measurements, Antithrombin Level, and Bleeding Amount during Cardiovascular Surgery and Intensive Care Unit Stay: A Observational Study
}

Mitsuharu Kodaka ( $\sim$ kmkodaka@cb3.so-net.ne.jp )

Tokyo Women's Medical University Medical Center East

Junko Ichikawa

Tokyo Women's Medical University Medical Center East

Kazuyoshi Ando

Tokyo Women's Medical University Medical Center East

Makiko Komori

Tokyo Women's Medical University Medical Center East

\section{Research Article}

Keywords: ROTEM, coagulopathy, cardiovascular anesthesia, antithrombin, Hepcon HMS Plus

Posted Date: January 13th, 2021

DOl: https://doi.org/10.21203/rs.3.rs-138067/v1

License: (c) (i) This work is licensed under a Creative Commons Attribution 4.0 International License. Read Full License 


\section{Abstract}

\section{Purpose:}

Hemoglobin levels after a cardiopulmonary bypass (CPB) are easily estimated; however, decreased fibrinogen and platelet levels before and after CPB are difficult to predict because of the adsorption and consumption. We hypothesized that fibrinogen levels, platelet count, and measurements by ROTEM ${ }^{T M}$ may decrease in proportion to CPB time; moreover, we compared the perioperative blood loss by conducting a observational study.

\section{Methods:}

A total of 160 patients were enrolled and divided into three groups depending on the CPB time: $<2,2-3$, and $>3 \mathrm{~h}$. Blood samples were obtained at four time points, i.e., baseline, CPB start, CPB end, and intensive care, and platelet counts, ROTEM, fibrinogen, and antithrombin were measured.

\section{Results:}

A total of 74 patients were included in the $<2 \mathrm{~h}, 63$ in the $2-3 \mathrm{~h}$, and 23 in the $>3 \mathrm{~h}$ groups.

No difference was observed in the platelet counts and fibrinogen between each group while weaning CPB, whereas the amplitude 10 min of EXTEM A10, FIBTEM A10, and antithrombin in the $>3 \mathrm{~h}$ group were lower than those in the other groups. Furthermore, blood loss and each transfusion component were higher in the $>3 \mathrm{~h}$ group than those in the other groups.

\section{Conclusions:}

The longer the CPB times, the greater perioperative bleeding loss and transfusion, particularly if $>3 \mathrm{~h}$, due to decreased (EXTEM A10 and FIBTEM A10) represented by ROTEM ${ }^{T M}$.

\section{Trial registration:}

This trial is registered with University hospital Medical Information Network (UMIN) Center, https://www.umin.ac.jp/. (ID: UMIN000017412) on May 5, 2015.

\section{Introduction}

Whole blood cells and other components are diluted in cardiac surgery with cardiopulmonary bypass (CPB). A dilution hemoglobin $(\mathrm{Hb})$ ratio can be calculated based on the amount of extracorporeal circulation filling and circulating volume [1]. Therefore, $\mathrm{Hb}$ level can be easily estimated after initiating CPB based on the dilution ratios of priming volume; however, decreased fibrinogen (Fib) and platelet levels before and after CPB are difficult to predict because of consideration of adsorption and consumption [2] in the extracorporeal membrane. 
Certain studies suggested that point-of-care (POC) tests, such as rotation thromboelastometry (ROTEM ${ }^{\mathrm{TM}}$ ) [3-6], and a hemostasis management system (Hepcon HMS Plus ${ }^{\mathrm{TM}}$ ) [7] can reflect real coagulopathy and reduce the requirements for hemostatic products along with shortening the hospital stay compared to conventional laboratory coagulation testing. Thus, we not only measured normal coagulation tests, including fibrinogen concentration, activated partial thromboplastin time, prothrombin time, antithrombin, and complete blood counts (CBC), but also fibrinogen polymerization and platelet counts represented by ROTEM $^{\mathrm{TM}}$. We first aimed to analyze these data in proportion to the CPB time. The second goal of the study was to compare the allogeneic blood transfusion rates, bleeding volumes, and perioperative outcomes during surgery and within the first $48 \mathrm{~h}$ after intensive care unit admission monitored using conventional laboratory testing and two POC tests: ROTEM ${ }^{\text {TM }}$ and Hepcon HMS Plus ${ }^{\mathrm{TM}}$.

We hypothesized whether fibrinogen, platelet count, antithrombin, and parameters measured by ROTEM ${ }^{\text {TM }}$ would decrease in proportion to CPB time. We also compared amounts of transfusion and the perioperative bleeding loss by conducting a case-control study.

\section{Material And Methods}

\section{Trial Design}

This observational, single-center study was conducted at Tokyo Women's Medical University, Medical Centre East, in accordance with the Declaration of Helsinki; was approved by the Institutional Review Board of the same institution (approval \#150207 on 10/9/2015); and was registered with the University Hospital Medical Information Network Centre (ID: UMIN000017412 on 5/5/2015). All patients provided written informed consent.

\section{Study Population}

A total of 160 patients who underwent cardiac surgery with CPB in October 2015-December 2018 were selected in this study. Exclusion criteria included emergency surgery, history of liver dysfunction, aged < 20 years, and pregnancy. Preoperative antiplatelet therapy except aspirin was terminated at least 7 days preoperatively. Warfarin and direct oral anticoagulants were terminated 2-4 days preoperatively, depending on guidelines [8]. Instead, heparin bridging with weight-adapted unfractionated heparin was administered intravenously until $6 \mathrm{~h}$ preoperatively.

\section{Anesthetic Management}

General anesthesia was induced with fentanyl $(0.2-0.3 \mathrm{mg})$, midazolam $(3-5 \mathrm{mg})$, and rocuronium bromide $\left(0.6 \mathrm{mg} \mathrm{kg}^{-1}\right)$. Intraoperative anesthesia was maintained with intravenous infusion of remifentanil (0.2-0.5 $\left.\mu \mathrm{g} \mathrm{kg}^{-1} \mathrm{~min}^{-1}\right)$, fentanyl with sevoflurane (1-3\%), and/or propofol (2-3 $\left.\mu \mathrm{g} \mathrm{ml}^{-1}\right)$ with target-controlled infusion (Diprifusor ${ }^{\mathrm{Tw}}$; Terumo, Tokyo, Japan). Patients were routinely monitored using a radial arterial line, bispectral index (Nihon Kohden, Tokyo, Japan), regional SO 2 (INVOS 5100C ${ }^{\text {TM. }}$ Edwards Lifesciences, Unterschleissheim, Germany), transesophageal echocardiography, central venous 
pressure, pulmonary artery pressure, continuous cardiac output, and $\mathrm{SvO}_{2}$ (Vigilance II ${ }^{\mathrm{TM}}$; Edwards Lifesciences). Tranexamic acid $(2-3 \mathrm{~g})$ was routinely administered before and after the CPB.

\section{Management of Extracorporeal Circulation}

The extracorporeal circuit consisted of a membrane oxygenator (CAPIOX FX15/ 25 $5^{\mathrm{Tm}}$; Terumo, Tokyo, Japan) and centrifugal pump (CAPIOX ${ }^{\mathrm{TM}}$; Terumo, Tokyo, Japan) with a heat exchanger. The circuit was primed with crystalloid solution (600-800 ml) (Physio 140 Injection $^{\mathrm{T}}$; Otsuka Pharm Co., Tokyo, Japan), mannitol $(200 \mathrm{ml})$, cefazolin $(4 \mathrm{~g})$, and betamethasone sodium phosphate $(5 \mathrm{mg})$ (Rinderon $\left.{ }^{\mathrm{TM}}\right)$. During $\mathrm{CPB}$, the non-pulsatile flow was maintained at 2.2-2.5 $\mathrm{I} \mathrm{min}^{-1} \mathrm{~m}^{-2}$, and the target mean arterial pressure was $50-70 \mathrm{mmHg}$. The initial myocardial protection was achieved with a crystalloid $\left(4^{\circ} \mathrm{C}\right)$ at $10 \mathrm{ml} \mathrm{kg}^{-1}$, followed by antegrade cold blood cardioplegia at $500 \mathrm{ml}$ (crystalloid: blood $=1: 4$ at $20^{\circ} \mathrm{C}$ ) every 30 min. Anti-fibrinolytic therapy consisted of $1 \mathrm{~g}$ of tranexamic acid after the induction of anesthesia and another $1 \mathrm{~g}$ after the administration of unfractionated heparin. CPB was performed in mild hypothermia $\left(33^{\circ} \mathrm{C}-\right.$ $\left.34^{\circ} \mathrm{C}\right)$ or deep hypothermic circulatory arrest $\left(24^{\circ} \mathrm{C}-29^{\circ} \mathrm{C}\right)$ only for a total or hemi-arch replacement.

Patients were divided into four groups depending on the CPB time: $<1,1-2,2-3$, and $>3 \mathrm{~h}$. Blood samples were obtained at four time points: baseline (before anesthesia induction), immediately after starting $C P B$, while weaning from $C P B$, and in the intensive care unit (ICU), and $C B C$, ROTEM ${ }^{\mathrm{TM}}[3-6]$ were obtained in all study groups. Hepcon HMS Plus ${ }^{\mathrm{TM}}[7]$ was used to calculate the appropriate unfractionated heparin dose if we set the patients' body weight and target activated clotting time (ACT; i.e., $450 \mathrm{~s}$ ) according to control blood samples within the target normal range. Hemostatic therapy comprised packed red blood cells (PRBCs), fresh frozen plasma (FFP), and platelet concentrate (PC). In Japan, one unit of these transfusion products is derived from $200 \mathrm{ml}$ blood. For ROTEM ${ }^{\mathrm{TM}}$ measurements, samples were collected at the same four time points. ROTEM ${ }^{\mathrm{TM}}$ algorithms were based on three tests: the EXTEM (reflecting extrinsic initiation), INTEM (reflecting intrinsic initiation), and FIBTEM (platelet-inhibited extrinsic activation, reflecting the contribution of fibrin polymerization to clot firmness). The clotting time (CT) in EXTEM and INTEM tests and the amplitude of clot firmness at $10 \mathrm{~min}$ (A10) were used to determine the transfusion $[9,10]$, such as PRBCs, FFP, and PC.

\section{The Main Algorism for Transfusion}

The target $\mathrm{Hb}$ concentration was 9-10 $\mathrm{mg} \mathrm{dl}^{-1}$, and the FFP dose was estimated according to previous studies $[9,10]$ to achieve a FIBTEM A10 of $>8-11 \mathrm{~mm}$. These studies suggested that approximately $4 \mathrm{ml}$ $\mathrm{kg}^{-1}$ of FFP increases the FIBTEM A10 by $1 \mathrm{~mm}$. The PC dose was also calculated according to a study to achieve an EXTEM A10 of $>40 \mathrm{~mm}$ [9] and/ or platelet count $>5-100,000 / \mathrm{ul}$. If either the CT of INTEM or/and ACT measured using Hepcon ${ }^{T M}$ was prolonged after protamine administration, we administered an additional protamine calculated using $\mathrm{Hepcon}^{\mathrm{TM}}$ after CPB. We did not administer any other additional blood products, such as fibrinogen concentrate, cryoprecipitate, and prothrombin complex concentrate.

\section{Cell-Saver Usage and Surgical Re-exploration}


A Cell-Saver $5^{\text {TM }}$ (Hemonetics Japan, Tokyo, Japan) was used to salvage washed erythrocytes for transfusion. Surgical re-exploration was performed if the total chest drain-tube blood loss exceeded $200 \mathrm{ml} \mathrm{h}^{-1}$ or hemopericardium occurred in the ICU as diagnosed with ultrasound and X-ray.

The number of transfused units (PRBCs, FFP, and PC) and blood loss intraoperatively and in the first $48 \mathrm{~h}$ after ICU admission are the primary outcome variables.

Statistical analyses were performed using JMP ver.15J (SAS Institute Japan, Tokyo, Japan). Data were assessed using analysis of variance and Tukey-Kramer's HSD test between groups. Statistical significance was defined as $P<0.05$. Preliminary power analysis setting $a=0.05, \beta=0.8$, effect size; $f=$ 0.25 and number of groups; 3 suggested $n=159$ calculated by statistical software, $G^{*}$ power [11].

\section{Results}

One patient had $<1 \mathrm{~h}, 73$ had $1-2 \mathrm{~h}, 63 \mathrm{had} 2-3 \mathrm{~h}$, and $23 \mathrm{had}>3 \mathrm{~h}$ CPB time. Therefore, as only one patient had $<1 \mathrm{~h}$, he was included in the $1-2 \mathrm{~h}$ group and renamed as $<2 \mathrm{~h}$ CPB group resulting in 74 cases. Patient characteristics are presented in Table 1. There was no significance except that between the EuroSCORE II of the CPB groups $<2 \mathrm{~h}$ and $>3 \mathrm{~h}$. Blood loss in the operating room (OR) and ICU was significantly higher in proportion to CPB time as shown in Fig. 1, and components of $\mathrm{CPB}>3 \mathrm{~h}$ for transfusion, i.e., FFP and PC in OR and RBCs and FFP in ICU, were significantly higher than the other two groups (Table 2); however, no significant differences were observed in platelet counts and fibrinogen levels between groups at weaning from CPB (Figs. 2). Furthermore, antithrombin, A10 of EXTEM and FIBTEM were lower in the $>3 \mathrm{~h}$ group than those in the other two groups at weaning of CPB (Figs. 2 and 3 ). Two patients with CPB of $2-3 \mathrm{~h}$ and one patient with $>3 \mathrm{~h}$ required reoperation for bleeding. 
Table 1

Patient characteristics

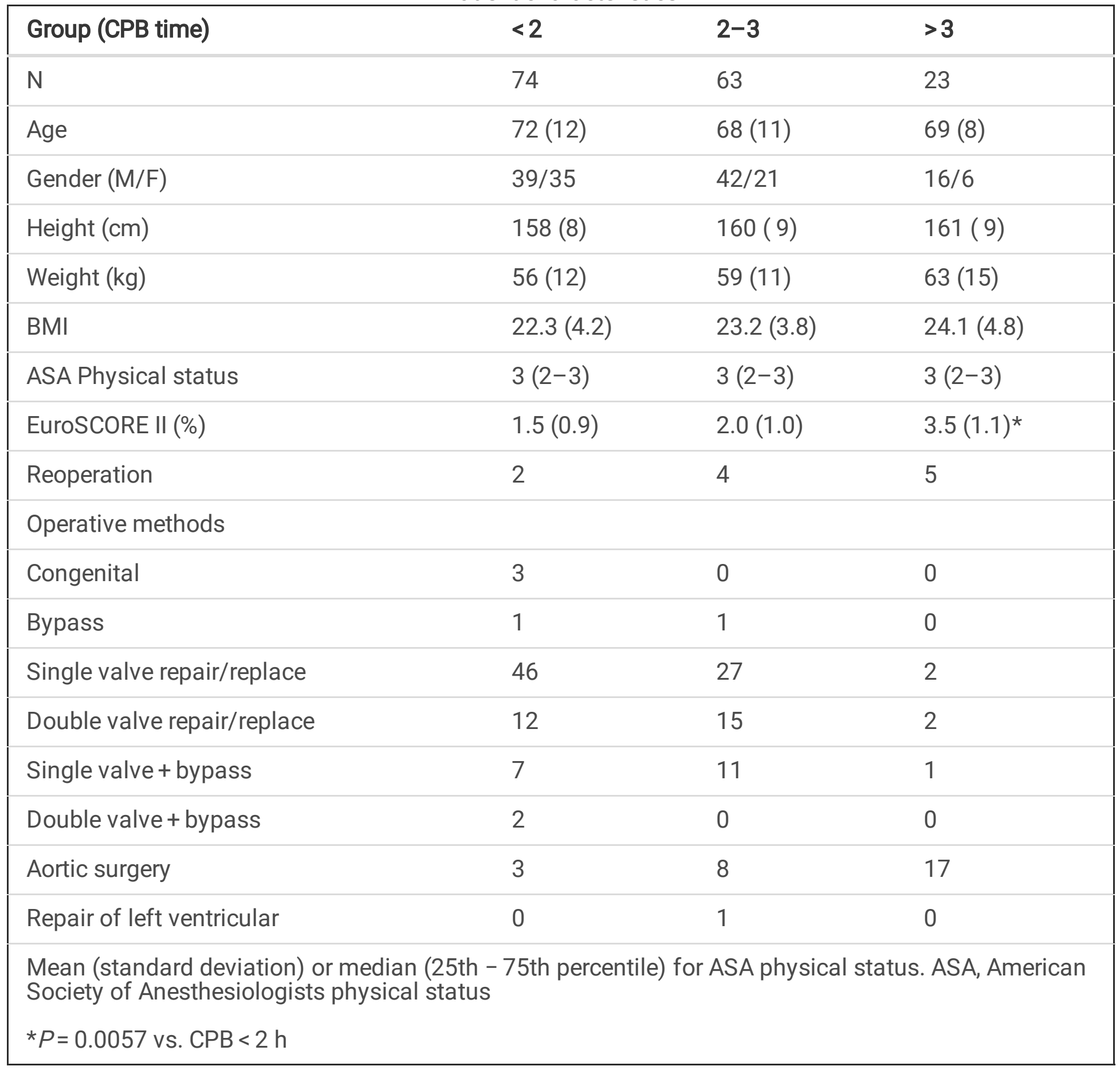


Table 2

Amount of blood transfusion in operating room (OR) and intensive care unit (ICU).

\begin{tabular}{|c|c|c|c|c|}
\hline \multicolumn{2}{|c|}{ CPB time (h) } & $<2$ & $2-3$ & $>3$ \\
\hline \multirow[t]{2}{*}{ PRBCs } & OR & $4(0-8)$ & $6(0-8)$ & $6(0-10)$ \\
\hline & $\mathrm{ICU}$ & $0(0-0)$ & $0(0-0)$ & $3(0-6.5)^{\star \#}$ \\
\hline \multirow[t]{2}{*}{ FFP } & OR & $0(0-3)$ & $0(0-6)$ & $8(0-14)^{* \#}$ \\
\hline & $\mathrm{ICU}$ & $0(0-0)$ & $0(0-0)$ & $0(0-3.5)^{\$ \&}$ \\
\hline \multirow[t]{2}{*}{ PC } & $\mathrm{OR}$ & $0(0-0)$ & $0(0-0)$ & $10(0-20)^{\star \#}$ \\
\hline & $\mathrm{ICU}$ & $0(0-0)$ & $0(0-0)$ & $0(0-0)$ \\
\hline \multicolumn{5}{|c|}{ Median (25th - 75th percentile) } \\
\hline \multicolumn{5}{|c|}{$\star P<0.0001, \${ }^{\$} P<0.01$ vs. CPB $<2$} \\
\hline \multicolumn{5}{|c|}{${ }^{\#} P<0.0005,{ }^{\&} P<0.01$ vs. CPB $2-3$} \\
\hline
\end{tabular}

However, no difference in $\mathrm{Hb}$, Fib, and platelet count was observed between groups at all four measuring points (all data were not shown).

\section{Discussion}

Blood loss in cardiovascular surgery in the OR and ICU was higher in proportion to the CPB time, particularly in the $>3 \mathrm{~h}$ group, i.e., 6.2 and 3.1 times, respectively, higher than in the $<2 \mathrm{~h}$ group. Differences in platelet counts and fibrinogen levels among groups were not significant, but ROTEM ${ }^{\mathrm{TM}}$ measurement use showed a significant reduction in EXTEM and FIBTEM A10 at CPB termination, which are said to reflect the platelet counts and fibrinogen polymerization [9].

Based on the study, we suggest that blood transfusion management using ROTEM ${ }^{\text {TM }}$ might be necessary if CPB time is $>3 \mathrm{~h}$, such as aortic surgery, to add EXTEM and FIBTEM parameters as transfusion algorithms. Therefore, if $\mathrm{CPB}$ time can be predicted to be $>3 \mathrm{~h}$ perioperatively, we would measure not only $\mathrm{CBC}$ and fibrinogen but also parameters by POC, i.e., ROTEM to determine whether the amount of preparation, such as FFP and PCs, would be enough or not preoperatively.

Haensig et al.[12] also reported that POC was effective if CPB time was > 115 min. However, Girdauskas et al.[13] reported that POC was more useful for the surgery with deep hypothermic circulatory arrest (DHCA), with an average CPB time of approximately $200 \mathrm{~min}$. In brief, they suggested that longer CPB time was more valuable for the measurement of POC coagulation test, which reduced the incidence of 
massive transfusion. However, only few studies investigated the relationship between CPB time, bleeding volume, and platelet function using POC, such as ROTEM.

Based on this study, two possible causes of reduced EXTEM and FIBTEM A10 were identified as represented by ROTEM. The first one was decreased antithrombin level. As shown in Fig. 2, when CPB exceeded $3 \mathrm{~h}$, antithrombin was significantly lower than those in the other CPB time groups. The low antithrombin level might reduce the effectiveness of heparin, resulting in platelet activation and consequently reducing platelet function following the CPB termination [14]. The second reason was based on DHCA. As shown in Table 1, most surgery types with $>3 \mathrm{~h}$ CPB were aortic surgeries such as total and hemi-arch replacement that required DHCA which could be reflected not by ASA physical status but EuroSCORE II as well. Moreover, the body temperature in DHCA was approximately $25^{\circ} \mathrm{C}-29^{\circ} \mathrm{C}$ in our hospital, requiring longer time for cooling and rewarming. It is generally said that platelet function is markedly impaired by hypothermia because of inactivation of enzyme insides the platelet [15]. Its hemostatic inability is known to be reversible; therefore, sufficient rewarming can also recover the platelet function. We regularly terminate $\mathrm{CPB}$ when the rectal temperature exceeded $36^{\circ} \mathrm{C}$ in DHCA cases; however, recovery of rectal temperature did not always coincide with the recovery of platelet function, showing time discrepancy. Based on these perspectives, the minimum temperature of DHCA tended to be higher in recent years. Therefore, if DHCA cases were excluded from patients in the CPB of $>3 \mathrm{~h}$ group, the group that only included mainly re-do or multi-valve replacement surgeries, decreased platelet function might not occur that often.

The measurement cost of POC test should also be considered because these tests are expensive, amounting to 20-30 US\$ for each test. Moreover, the most recent POC tests have been changed into

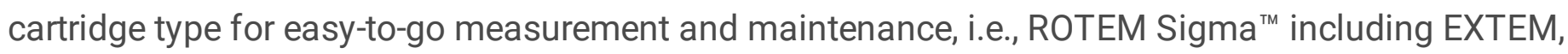
INTEM, Heptem, and Aptem, amounting to approximately 100 US\$.

Several studies have already investigated the usefulness of POC tests to reduce perioperative bleeding, transfusions, and cost for cardiac surgery and trauma patients [16]. Moreover, a recent multicenter study investigated a higher number of patients, i.e., 7402 cardiac surgeries with routine POC algorithm, who have been proven to have reduced major bleeding and PRBCs transfusion and PC [17].

By contrast, based on the results of our study, routine protocol for applying the POC test did not seem to be cost effective [18]. Therefore, patients with longer CPB time, with higher risk factors i.e., higher EuroSCORE II, and who used antiplatelet medications and coagulants should be carefully selected for the measurement of POC test because of high cartridge costs. Cardiac surgeries with CPB time of $<3 \mathrm{~h}$ do not require routine $\mathrm{POC}$ test but require sufficient usual laboratory $\mathrm{CBC}$ and coagulation tests including Fib.

Limitations of this study include the small number of patients as an observational study. The influence of DHCA for the $>3 \mathrm{~h}$ group could not be excluded. We noted that patients undergoing DHCA were weaned from CPB at a lower temperature, and this might affect platelet counts and function represented by the ROTEM measurements [19]. If patients with DHCA were excluded, platelet dysfunction may have been 
lower than that of our data. Only elective cardiac cases were included in this case-control study, and those who underwent emergency aortic dissection were excluded. Longer periods of hospital courses, including any complications, i.e., length of artificial ventilation, kidney injury, and neurological deficits, should also be considered.

\section{Conclusion}

Perioperative bleeding loss and amount of transfusion have been increased in proportion to CPB time mainly because of lower antithrombin levels and platelet counts and fibrinogen polymerization represented by ROTEM $^{\text {TM }}$ measurement values, such as EXTEM and FIBTEM A10.

\section{Abbreviations}

CPB: cardiopulmonary bypass; Hb: hemoglobin; Fib: fibrinogen; POC: point-of-care; ROTEM ${ }^{\mathrm{T}}$ : rotation thromboelastometry; Hepcon HMS Plus ${ }^{\mathrm{T} w}$ : hemostasis management system; CBC: complete blood counts; ICU: intensive care unit; ACT: activated clotting time; PRBCs: packed red blood cells; FFP: fresh frozen plasma; PC: platelet concentrate; CT: clotting time; OR: operating room; DHCA: deep hypothermic circulatory arrest

\section{Declarations}

\section{Acknowledgments}

We thank Enago (www.enago.jp) for the English language review of this manuscript.

\section{Authors' contributions}

M.K. participated in patient recruitment, data collection, and writing of the first draft of the manuscript. J.I. participated in study design and data analysis. K.A. contributed to patient recruitment and data collection. M.K. drafted the final manuscript version to be published. All authors reviewed the manuscript.

\section{Funding}

The author(s) received no financial support for the research, authorship, and/ or publication of this article.

\section{Availability of data and materials}

The datasets analyzed during the current study are available from the corresponding author on reasonable request. 


\section{Ethics approval and consent to participate}

The study was approved by Institutional Review Board of Tokyo Women's Medical University (Approved \# 150207 and date 10/9/2015) and registered with University hospital Medical Information Network (UMIN) Center, https://www.umin.ac.jp/. (ID: UMIN000017412) on May 5, 2015. The patients agreed to participate in the study voluntarily. After they were informed about the potential risks and predicted results of the study, they completed the written informed consent forms.

\section{Consent for publication}

Not applicable.

\section{Competing interests}

The authors declare that they have no competing interests.

\section{References}

1. Messmer K. Hemodilution. Surg Clin North Am 1975; 55: 659-678.

2. Garvin S, Fitzgerald D, Muehlschlegel JD, Perry TE, Fox AA, Shernan SK, et al. Heparin dose response is independent of preoperative antithrombin activity in patients undergoing coronary artery bypass graft surgery using low heparin concentrations. Anesth Analg 2010; 111: 856-861.

3. Ichikawa J, Kodaka M, Kitahara T, Sato N, Nishiyama K, Nakano K et al. The use of thromboelastometry and tranexamic acid reduces blood loss and transfusion requirements in cardiac surgery under cardiopulmonary bypass (in Japanese). Masui 2015; 64: 131-

4. Görlinger K, Dirkmann D, Hanke AA, Kamler M, Kottenberg E, Thielmann M, et al. First-line therapy with coagulation factor concentrates combined with point-of-care coagulation testing is associated with decreased allogeneic blood transfusion in cardiovascular surgery: a retrospective, single-center cohort study. Anesthesiology 2011; 115: 1179-1191.

5. Ichikawa J, Marubuchi T, Nishiyama K, Kodaka M, Görlinger K, Ozaki M, et al. Introduction of thromboelastometry-guided administration of fresh-frozen plasma is associated with decreased allogeneic blood transfusions and post-operative blood loss in cardiopulmonary-bypass surgery. Blood Transfus 2018; 16: 244-252.

6. Kawashima S, Suzuki Y, Sato T, Kikura M, Katoh T, Sato S, et al. Four-group classification based on fibrinogen level and fibrin polymerization associated with postoperative bleeding in cardiac surgery. Clin Appl Thromb Hemost 2016; 22: 648-655. 
7. Wang J, Ma HP and Zheng H. Blood loss after cardiopulmonary bypass, standard vs titrated protamine: a meta-analysis. Neth J Med 2013; 71: 123-

8. Eagle KA, Guyton RA, Davidoff R, Ewy GA, Fonger J, Gardner TJ, et al. ACC/AHA guidelines for coronary artery bypass graft surgery: Executive summary and recommendations. A report of the American College of Cardiology/American Heart Association task force on practice guidelines (committee to revise the 1991 guidelines for coronary artery bypass graft surgery). Circulation 1999; 100: 1464-1480.

9. Solomon C, Pichlmaier U, Schoechl H, Hagl C, Raymondos K, Scheinichen D, et al. Recovery of fibrinogen after administration of fibrinogen concentrate to patients with severe bleeding after cardiopulmonary bypass surgery. Br J Anaesth 2010; 104: 555-562.

10. Sato T, Kawashima S, Suzuki Y, Kikura M, Takatoku K, Hirama D, et al. Thromboelastometry $\left(\right.$ ROTEM $\left.^{\mathrm{T} M}\right)$, fibrinogen concentration and platelet counts during cardiopulmonary bypass predict perioperative requirements for blood transfusion in cardiac surgery (in Japanese with English abstract). Cardiovascular Anesthesia 2015; 19: 49-54.

11. G*Power: Statistical Power Analyses for Windows and Mac. http://gpower.hhu.de/ (Accessed on: 5 June 2020).

12. Haensig M, Kempfert J, Kempfert PM, Girdauskas E, Borger MA, Lehmann S, et al. Thrombelastometry guided blood-component therapy after cardiac surgery: a randomized study. BMC Anesthesiol 2019; 19: 201.

13. Girdauskas E, Kempfert J, Kuntze T, Borger MA, Enders J, Fassl J, et al. Thromboelastometrically guided transfusion protocol during aortic surgery with circulatory arrest: a prospective, randomized trial. J Thorac Cardiovasc Surg 2010; 140: 1117-1124.

14. Sniecinski R, Szlam F, Chen EP, Bader SO, Levy JH, Tanaka KA. Antithrombin deficiency increases thrombin activity after prolonged cardiopulmonary bypass. Anesth Analg 2008; 106: 713-718.

15. Wolberg AS, Meng ZH, Monroe DM 3rd, Hoffman M. A systematic evaluation of the effect of temperature on coagulation enzyme activity and platelet function. J Trauma 2004; 56: 1221-1228.

16. Wikkelsø A, Wetterslev J, Møller AM, Afshari A. Thromboelastography (TEG) or rotational thromboelastometry (ROTEM) to monitor haemostatic treatment in bleeding patients: a systematic review with meta-analysis and trial sequential analysis. Anaesthesia 2017; 72: 519-531.

17. Karkouti K, Callum J, Wijeysundera DN, Rao V, Crowther M, Grocott HP, et al. Point-of-care hemostatic testing in cardiac surgery: a stepped-wedge clustered randomized controlled trial. Circulation 2016; 134: 1152-1162.

18. Serraino GF, Murphy GJ. Routine use of viscoelastic blood tests for diagnosis and treatment of coagulopathic bleeding in cardiac surgery: updated systematic review and meta-analysis. $\mathrm{Br} \mathrm{J}$ Anaesth 2017; 118: 823-833.

19. Kodaka M, Osada Y, Samejima Y, Komori M. Does deep hypothermic cardiac arrest affect platelet function? Eur J Anaesthesiol 2019; 36 (e-supplement 57): 271 
Figures
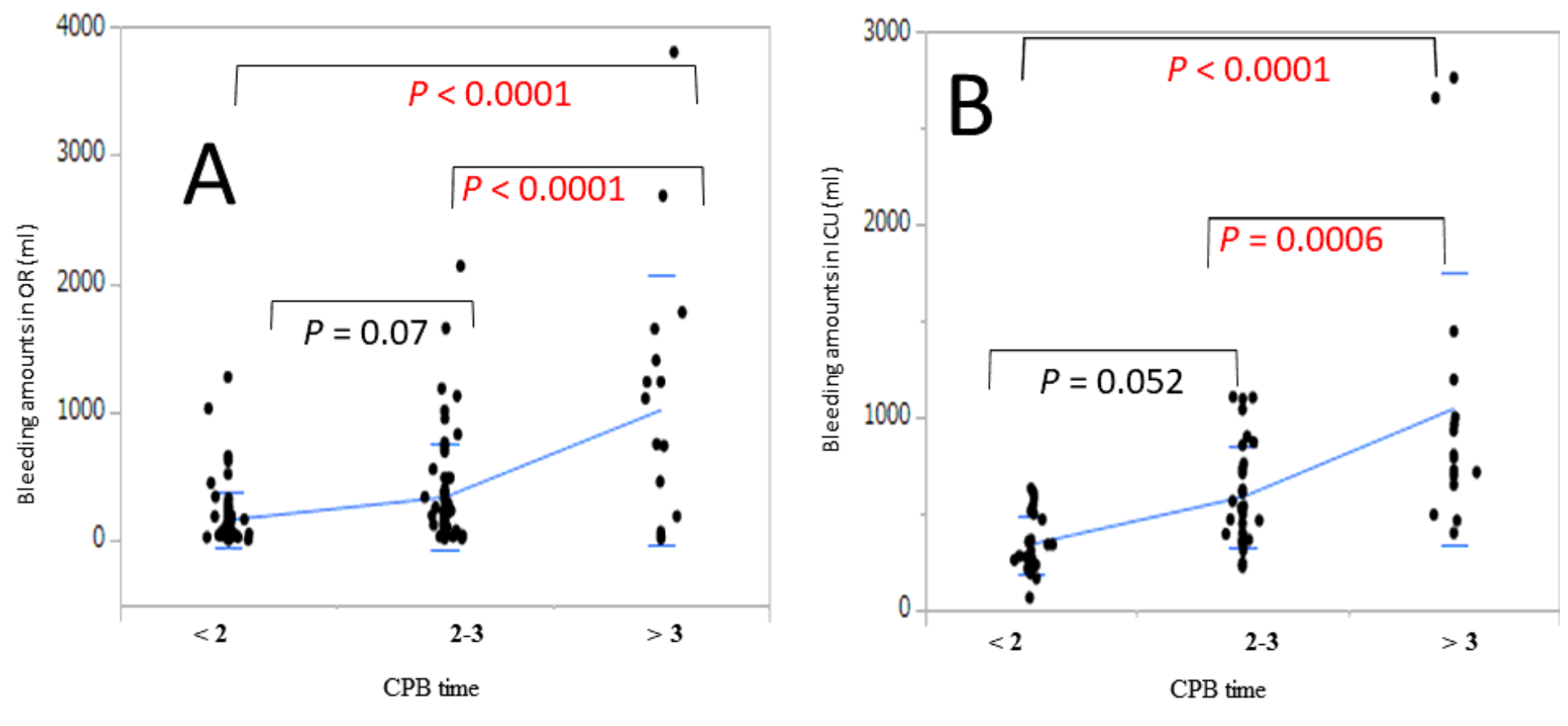

$\begin{array}{lrl}\text { CPB time } & \text { Mean } & (\text { SD }) \\ <2 & 163 & (218) \\ 2-3 & 339 & (410) \\ >3 & 1016 & (1050)\end{array}$

$\begin{array}{lrl}\text { CPB time } & \text { Mean } & (\text { SD }) \\ <2 & 341 & (150) \\ 2-3 & 585 & (265) \\ >3 & 1043 & (702)\end{array}$

\section{Figure 1}

Figure 1

$A$ : CPB time and bleeding in the OR. Each dot represents the value, and blue lines indicate mean and standard deviation. B: CPB time and total bleeding in the ICU. 

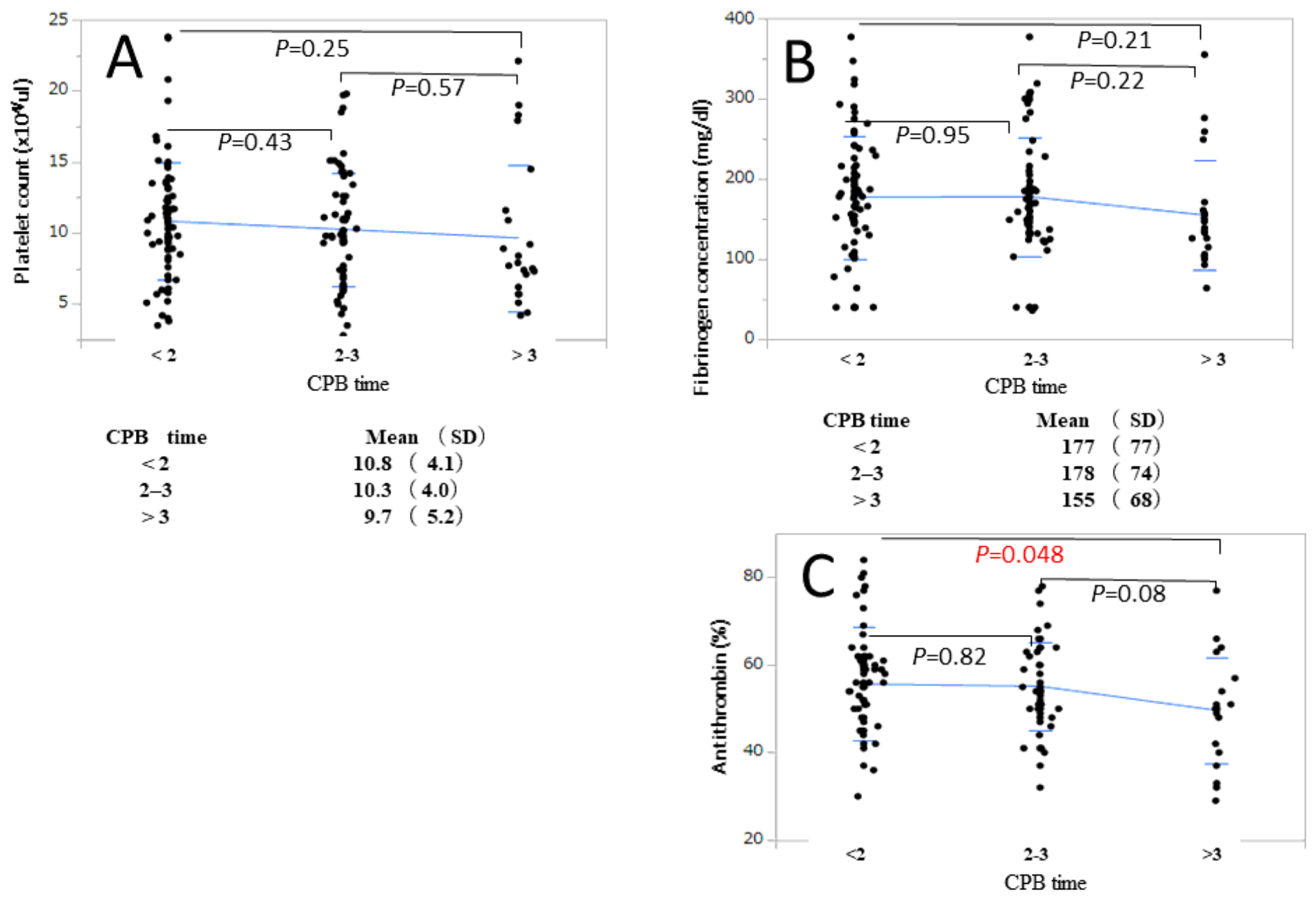

Figure 2

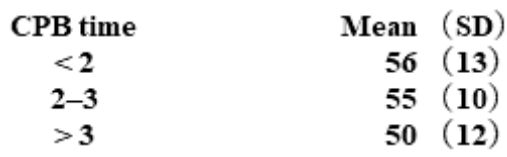

Figure 2

A: CPB time and platelet counts at the end of CPB. B: CPB time and fibrinogen level at the end of CPB. C: $\mathrm{CPB}$ time and antithrombin level at the end of CPB. 

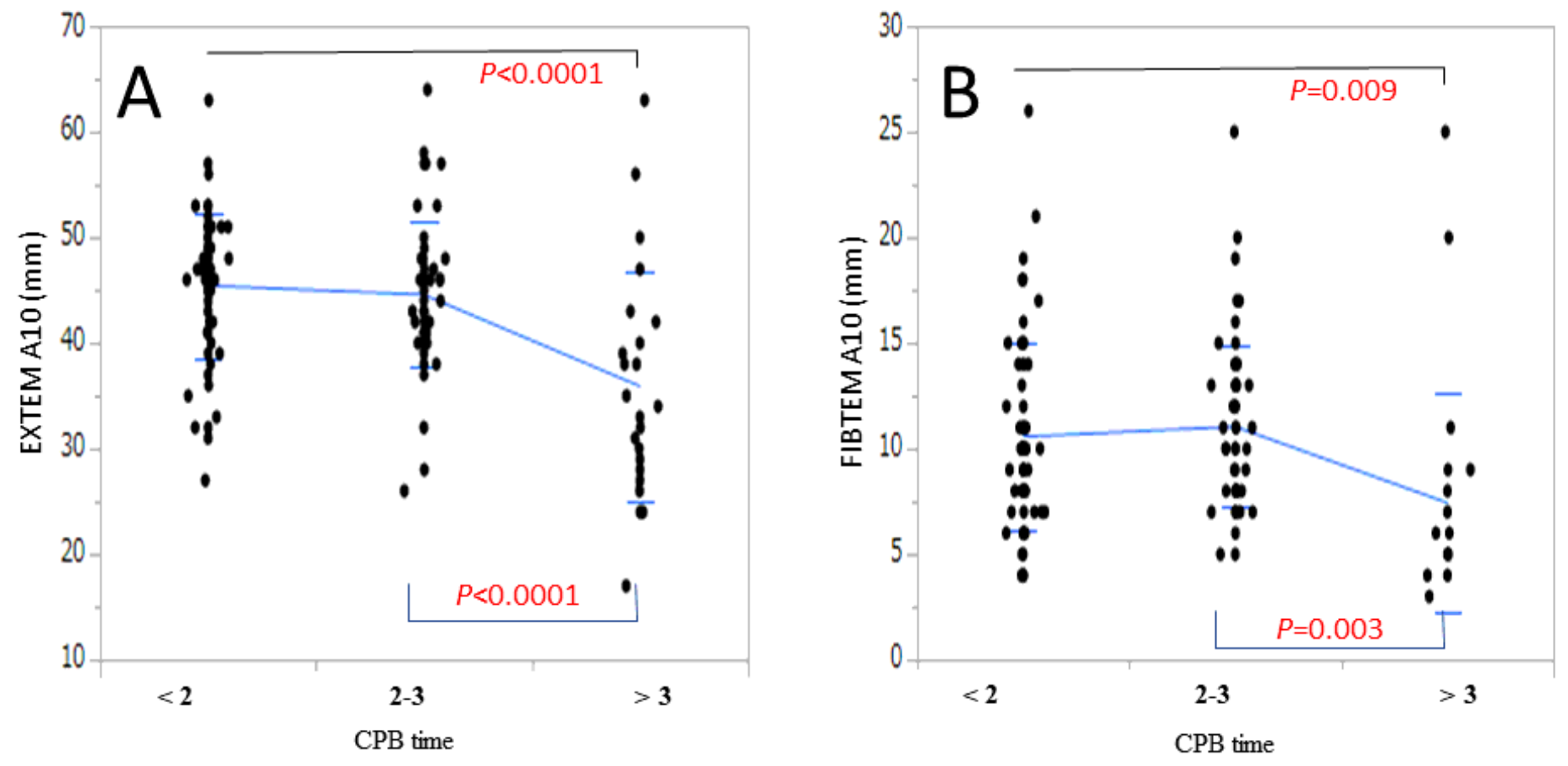

$\begin{array}{cr}\text { CPB time } & \text { Mean }(\text { SD }) \\ <2 & 48(6) \\ 2-3 & 47(6) \\ >3 & 42(8)\end{array}$

$\begin{array}{cr}\text { CPB time } & \text { Mean (SD) } \\ <2 & 11(4) \\ 2-3 & 11(4) \\ >3 & 9(5)\end{array}$

Figure 3

Figure 3

A: CPB time and EXTEM A10 at the end of CPB. B: CPB time and FIBTEM A10 at the end of CPB. 